\title{
Brief Discussion on the Use of New Fabrics in Home Clothing Design
}

\author{
Chunna Li \\ College of Art and Apparel, Tianjin Polytechnic University \\ Tianjin 300387, China \\ E-mail: naande@sohu.com \\ Dali Ma \\ College of Art and Apparel, Tianjin Polytechnic University \\ Tianjin 300387, China
}

\begin{abstract}
This paper discusses the relationship between fabrics and clothing and advances the fabric factor in home clothing design. Considering the specific characteristics of new fabrics, this paper analyzes the uses of new fabrics in home clothing design, aiming at promoting the use of new fabrics in home clothing. This paper serves as a reference and direction for home clothing design in a sense.
\end{abstract}

Keywords: New fabric, Home clothing, Color cotton, Bamboo fiber, Modal

Along with the development of the time, most citizens pursue for the quality of family life. Accompanied with this pursuit, home clothing keeps in changing. It shows a splendid future. Many fashion brands enter this field gradually. And home clothing tends to be more fashion. Modern apparel design theory agrees that fabric is an important element in apparel aesthetics. Apparel design, in a sense, is to develop the aesthetic characteristics of fabrics completely. Apparel development history also proves that the reform of materials usually brings about new chances and vitalities, causing the change of fashion and promoting the development of apparel industry. The home clothing design is not an exception. Therefore, to take advantage of fabrics turns into a weapon of home clothing design.

\section{The relationship between apparel and fabric in apparel development}

Pierre Cardin, who pursues for new clothing fabrics and new fashion, has said: "During the history development of apparel and textiles, there is always a closely associated relationship."

\subsection{The reform of apparel concept causes the update of clothing fabrics}

The improvement of clothing fabrics and the creative master is the key for apparel design. From the ancient time to now, as people change their apparel aesthetics, the clothing fabrics will be affected more or less. Japanese fashion designer Issey Miyake who has a unique eye toward apparel determines to get rid of restrictions from the western culture and explore new inspirations from the eastern culture. He firstly applies a fabric with tiny, ordered, and closely-pleated fabric to the design. The application of this fabric becomes the symbol of deconstruction fashion popular in the world. The apparel made of fabrics with pleats has a special appearance, which is fitting and loose, brightening all people's eyes. It soon becomes a symbol of people pursuing for freedom and coziness. From Issey Miyake's designs, we can notice not only the new thought of apparel design but also the changes of clothing fabrics caused by new apparel design idea.

1.2 The appearance of new clothing fabrics drives the change of apparel style.

The fast development of science and technology brings about unprecedented changes. Many countries develop new fibers based on the rich fiber resources. New textile fabrics appear frequently. Sorts of fabrics update the apparel, offering material bases and guaranty for the prosperity of apparel. Every excellent apparel designer pays attention to the latest change of clothing fabric, identifying and grasping the wider design spaces originated from new fabrics. 
As the world famous Dupont produced the elastic fabrics with Lycra, the flexibility of fabrics has been improved greatly. In design, a fit tailoring will be more appreciated. Meanwhile, new assistant clothing fabrics impact the style of apparel to a great degree. The thinner and lighter fabrics are gradually changing traditional western apparel's strong appearance, becoming more soft and comfortable.

\section{The fabric factor in home clothing design}

Due to the shortening of fashion cycle, the improvement of science and technology, and the severe competition between industries, clothing fabrics tend to be more colorful, which offers a wide space for designers. The primary precondition for home clothing is the comfort. It should make people feel comfortable. Secondly, a market survey shows that although traditional pure cotton serves as the main fabrics for home clothing, they mostly crowd in low and middle market. To take the high-grade market, it is necessary to master the fashion trend of fabrics.

\subsection{The comfortable factor of fabrics}

Home clothing is for a special family atmosphere. The coziness is the fundamental factor. As people are in home clothing, they want to enjoy the special pleasure and relaxation at home. Therefore, in choosing fabrics for home clothing, we usually prefer to skin-friendly type. And knitting fabric is better than woven fabric. Elastic fabric is better than non-elastic fabric. Although home clothing is not necessarily close to the skin, as the underwear, it has a higher requirement for hygiene than other type of clothing. The anti-virus, water-absorbing, and fast-drying fabric can satisfy this need to a great degree. Along with the constant upgrade of fabrics, people pursue for products endowed with new technologies more and more. Pure cotton fabric could not satisfy people's needs. The cotton woven fabric, the green environment-friendly fabric, and the functional fabric have already become the new favorites of apparel designers.

\subsection{The popular factor of fabrics}

The apparel popularization and the fabric popularization are one united body. Fabrics' popularization change is one aspect of apparel style, and also an irreplaceable motive for apparel design. An apparel designer should pay attention to latest fabric information, understanding the fashion trend inside and outside, including the clothing fabrics, in time, and judging and adjusting the design according to the fashion of clothing fabrics. As fashion predictors discuss the popular color of next season, they always take colors, patterns, and other clothing fabric factors into consideration. Under some circumstances, the popular apparel reflects the update of clothing fabrics and the change of techniques. For example, as we design summer home clothing for ladies, we should know that the natural color cotton, clean silk, and new green fiber fabric are popular fabrics for home clothing now. The fabrics should have the cotton pattern, the warm small flowers, and classic flower pattern. To design based on these popular fabric, designers will grasp the fashion trend easily.

\section{The use of new fabrics in home clothing design}

\subsection{The use of bamboo fiber fabric in home clothing design}

The bamboo fiber is one of re-produced fiber. It is made of bamboo by means of high technologies. The bamboo fiber can endure hard rubs, without fluff, with moisture absorption and permeability. It feels soft and cool. People in clothes made of bamboo fiber will be more comfortable. Besides, the bamboo fiber is anti-virus and environment-friendly, with bright colors, satisfying people's needs today. The home clothing made of bamboo fiber can offer a comfortable feeling and defend virus, preventing skin diseases.

Considering these characteristics, the bamboo fiber is right for the spring and summer home clothing. Colors should be plain, inheriting bamboo's nature. Woven, knitted, or jacquard fabrics are better choices. The design should be simple and in good taste. Different tailoring can make the clothing fabrics and the clothing style in a great harmony. In designing the home clothing made of bamboo fiber, designers can adopt pleats or waves and other designs, adding comparisons to the work, making it more attracting.

\subsection{The use of natural color cotton in home clothing design}

Color cotton is from the natural color cotton, without man-made colors. Color cotton is not only pure natural fiber but also pure natural color. Color cotton follows strict production standards from planting, to knitting, to product. In detail, the planting is based on high biological techniques, without any poisons, such as fertilizer or pesticide. The knitting is free from traditional technological process, such as blanching, refining, or dying. The fiber and the clothes are "zero pollution". Therefore, color cotton meets for people's "green revolution", reducing the environmental pollution. Color cotton is pure green and environment-friendly product.

In design, it is better to maintain the natural feature of color cotton, which will make the cotton cloth more fashionable and beautiful. Because of the few colors of color cotton, the home clothing may not be colorful. Designers can show their talents in style. Separation and connection can be used for designing the style. Based on satisfying people's basic needs for comfort, it can realize a harmony of beauty and utility. The separation can be achieved by beeline, arc, and curve. The beeline conveys a sense of purity, stability, and strength, being a male taste. The arc tends to be smooth and 
stable. The curve, such as parabola and helix curve, is moveable, soft, and gentle. Lady clothing should be fitting, displaying the body beauty. In special, to integrate the seamless structure and the style design together will achieve an unexpected result. Considering the few colors of color cotton, we can mix two colors in one design. The mixed color design is one of separation. Two colors form different forms in structure, generating a balanced effect in sight and conveying a sense of beauty.

\subsection{The use of Modal in home clothing design}

Modal is a kind of cellulose fiber. It can be processed into a thread longer than silk, which is a best choice for super thinner fabric. Modal can be mixed with sort of fibers. It is changeable. With Modal, cotton will be softer. Bast fiber will be smoother. Wool will be more elastic. Silk will be easier to control. Synthetic fiber will be felt more natural. Modal home clothing is soft and gentle with elegant colors. It can absorb moisture well and has nice permeability. Modal fabrics are colorful and without static in body. After being washed many times, it still keeps bright color and soft. Therefore, it is an ideal fabric for home clothing.

Modal can be knitted with many other fibers. It is changeable. Therefore, with modal, we can develop many products in home clothing design. The light and thin Modal fabric can be used for skirts, one-piece dresses or dresses, and trousers with different matches. In design, we can add many different decorations, such as buds, pleats, and small bowknots, conveying a sense of pleasure, free, and warm. The Modal fabric can also used for winner clothes, especially for coats and trousers. The better elasticity makes it right for sports home clothing.

\section{Conclusion}

Along with the increasing pressure of life and work, more and more people would like to pursue for a warm, free, and relax home life. As a result, the needs for home clothing are rising gradually. They demand for high-quality home clothing. In designing home clothing, the reasonable use of apparel fabrics is vital for the whole clothes. It is a key factor for the home clothing brand conquering and mastering the market.

\section{References}

Liao, Qiuju \& Liu, Guolian. (2008). Textile Components and Application Shanghai: Donghua University.

Liu, Hui., Wang, Zhengui \& Yue, Haiying. (2008). Design of color cotton clothing. Journal of Xingtai Polytechnic College. No. 25(3).

Marrillyn Horn. (2000). The Second Skin. Shanghai: Shanghai People's Publishing House. 